\title{
8
}

\section{Changing Productive Structures}

\begin{abstract}
In this chapter, Cilliers offers various explanations for Africa's lack of sustained, structural economic transformation from low-value economic activities towards high-value services and manufacturing, and explores the challenges associated with the continent failing to industrialise. He offers historical context for how this situation emerged, drawing from global datasets such as trade data from the UN Conference on Trade and Development. The chapter then proceeds to look to the future of industrialisation in Africa in the context of technology-driven changes to the manufacturing sector globally via the fourth industrial revolution, which could offer the continent opportunities to gain a foothold in global value chains. The latter portion of the chapter models key interventions in a Made in Africa scenario, and examines its economic impact to 2040 .
\end{abstract}

Keywords Industrialisation - Trade - Deindustrialisation - Economic sophistication · Fourth industrial revolution - Digitisation - Services . Research and development . Productivity . China in Africa

\section{Learning Objectives}

- Explain the main characteristics of Africa's current economic profile in terms of the agricultural, services, manufacturing and energy sectors

- Understand why the ongoing dominance of low-end services sector could be problematic for Africa's economic future 
- Explain how global knowledge and technology diffusion is changing manufacturing

- Understand the role that China now plays in Africa's industrial development

- Recognise the main inputs, strategies and policy conditions needed to spur industrialisation in Africa.

With its fast-growing population, rapid economic growth is a prerequisite to reduce poverty and improve livelihoods in Africa. To rapidly grow, an economy needs to improve productivity in agriculture, industry and services. It also has to move labour and capital from a low-productivity sector like agriculture to a higher-productivity sector like manufacturing, as well as from the informal to the formal sector. Employment in the formal sector is particularly important for it improves stability, reduces inequality, and most importantly, contributes tax revenues that enable governments to invest in better health, more education and appropriate infrastructure.

The problem is that on current trends, much of sub-Saharan Africa's economic future is likely to consist of a large subsistence agricultural sector in rural areas and low-end, informal services in urban areas that generally consist of wholesale and retail trade. ${ }^{1}$

There is no silver bullet to improving productive structures (although digitisation can help). African countries are also very different from one another. But the common prerequisite is for an activist government that expands the country's human capital endowment, encourages labour-intensive (even gardening-style) small-scale agriculture; places an unrelenting focus on expanding its value-added exports (largely manufacturing) and orients economic policy, including the financial sector, towards improving productive capacity.

According to the World Bank, ${ }^{2}$ the services sector constituted more than half of economic activity in sub-Saharan Africa by value in 2018, while industry (including manufacturing at 10\%) constituted 25\%. Agriculture constituted $16 \% .^{3}$ The forecast within IFs is for a very steep increase in the

\footnotetext{
${ }^{1}$ Bhorat, H., Kanbur, R., Rooney, C., and Steenkamp, F., 2017. Sub-Saharan Africa's Manufacturing Sector: Building Complexity. African Development Bank Group, Working Paper Series No. 256, May. see also Newman, C., Page, J., Rand, J., Shimeles, A., Söderbom, M., Tarp, F., 2016. The Pursuit of Industry: Policies and Outcomes. In: Manufacturing Transformation: Comparative Studies of Industrial Development in Africa and Emerging Asia. Oxford University Press. See also Fox, L., Thomas, A. H., and Haines, C., 2017. Structural Transformation in Employment and Productivity: What Can Africa Hope For? Washington: International Monetary Fund.

${ }^{2}$ World Bank Open Data at https://data.worldbank.org/.

${ }^{3}$ Industry includes manufacturing, mining, electricity, water and gas. Agriculture includes livestock and crop production, forestry, hunting and fishing.
} 
size of the services sector to 2040, with manufacturing as a portion of gross domestic product (GDP) remaining stagnant and agriculture declining. That forecast, if accurate, is for a slow-growth Africa where the increase in the size of the population inevitably translates into a larger economy, but only slow improvements in average incomes since the growth of low-end services evident in much of Africa, does not really improve productive structure.

Low-end services - which is particularly dominant in urban Africa-were by 2010 only twice as productive as agriculture. ${ }^{4}$ Due to its marginally better levels of productivity, the growth in low-end services in Africa has done little to improve per capita incomes. 5

Estimates as to the levels of productivity in different economic sectors in Africa differ. Carol Newman and colleagues find that the manufacturing sector in Africa is six times more productive than agriculture. In his bestselling book Kicking away the ladder the South Korean author and academic Ha-Joon Chang described the view that developing countries can largely skip industrialisation and enter the post-industrial phase where services increasingly drive employment and productivity growth as 'a fantasy'. This is because the manufacturing sector has 'an inherently faster productivity growth than the services sector', ${ }^{6}$ he argues.

Beyond the various schools of economic theory, authors as diverse as Arthur Lewis, Erik Reinert, Calestous Juma and recently Dani Rodrik have written extensively on the importance of early industrialisation - and the significant role of governments/ruling elites in charting this course. A 2016 report prepared by the United Nations University World Institute for Development Economics Research (UNU-WIDER) explains the importance of industrialisation as follows:

Between 1950 and 2006, about half of the catch-up by developing countries to advanced economy levels of output per worker was explained by rising productivity within industry combined with structural transformation out of agriculture. Industry is the pre-eminent destination sector at early stages of

\footnotetext{
${ }^{4}$ Newman, C., Page, J., Rand, J., Shimeles, A., Söderbom, M., Tarp, F. 2016. The Pursuit of Industry: Policies and Outcomes. In: Manufacturing Transformation: Comparative Studies of Industrial Development in Africa and Emerging Asia. Oxford University Press, p. 5.

${ }^{5}$ The challenge, notes Carol Newham and her co-authors, is that 'the marginal productivity of new services workers is low and possibly negative'. Ibid.; see also Bhorat, H., Kanbur, R., Rooney, C., and Steenkamp, F., 2017. Sub-Saharan Africa’s Manufacturing Sector: Building Complexity. African Development Bank Group, Working Paper Series No 256, May, p. 5.

${ }^{6}$ Chang, H.-J., 2003. Kicking Away the Ladder: Development Strategy in Historical Perspective. London: Anthem Press, p. 43.
} 
development because it is a high productivity sector capable of absorbing large numbers of moderately skilled workers. ${ }^{7}$

The problem is that, in much of Africa, manufacturing is declining while the contribution from services is growing. The IFs Current Path forecast expects the services sector to contribute around $60 \%$ of GDP for low, lower-middle and upper-middle-income African countries by 2040. That trend mimics trends globally with transport, financial, health and recreation growing more rapidly than any other in terms of their contribution to global GDP across all country income groups, but services are set to grow particularly rapidly in Africa.

I have explained, in Chapter 2, that with a few exceptions, Africa tends to export unprocessed commodities such as coffee, cocoa and suchlike, and to import processed products and finished goods from the European Union, China and elsewhere. This trend is likely to continue, reflecting the limited value addition that is characteristic of most African economies.

The law of diminishing returns is that countries that specialise in supplying raw materials, unprocessed agricultural products or low-end services yield a progressively smaller return for every unit of capital or labour compared to the provision of value-added goods. For example, a recent study by the UN Conference on Trade and Development (UNCTAD) entitled Identifying and Promoting Regional Value Chains in Leather and Leather Products in Africa laments the fact that Africa is the largest source of hides and skins in the world but that these exports come with very little value addition. ${ }^{8}$ Like coffee (from Ethiopia of Kenya), 'Italian' handbags or shoes (often made from African leather) demand high prices but are not produced in Africa.

The growth that is based on increasing commodity exports, as opposed to exports of value-added products, cannot induce structural economic transformation. Instead it has led to high technology 'bubbles' or economic enclaves with very few linkages into the rest of the economy. Examples include the oil-producing parts of Angola off the coast of Cabinda, parts of oil-producing Nigeria (in the Niger delta), sections of Equatorial Guinea and soon areas in northern Mozambique with its rich natural gas endowment.

Compare this with the experience of rapidly developing Asian countries such as Japan, the Asian Tigers and Vietnam, where activist governments

\footnotetext{
${ }^{7}$ Newman, C., Page, J., Rand, J., Shimeles, A., Söderbom, M., Tarp, F., 2016. The Pursuit of Industry: Policies and Outcomes. In: Manufacturing Transformation: Comparative Studies of Industrial Development in Africa and Emerging Asia. Oxford University Press, p. 5.

${ }^{8}$ Banga,. R., Kumar, D., and Cobbina, P., 2018. Identifying and Promoting Regional Value Chains in Leather and Leather Products in Africa. Geneva: United Nations Conference on Trade and Development.
} 
encouraged growth in the manufacturing sector and their entry into global value chains that served to steadily improve the quality and productivity of the associated goods. In this manner, these countries steadily upgraded their technical capabilities to meet global standards, often by inviting and partnering with multinational companies for the transfer of technology, skills and knowledge. ${ }^{\text {? }}$

Today global value chains are again evolving rapidly and offer opportunities for Africa, which is generally only peripherally part of these chains. First, modern technology offers significant opportunities for industrial latecomers to skip over the brick and mortar institutions of yesterday into a world where banking and sourcing of inputs are done remotely, while benefiting from a decline in the financial investment that is required to embark upon manufacturing. Second, there are signs of increased manufacturing nationalism (leading to the so-called reshoring of manufacturing back to the 'home' country) that has accompanied concerns in the USA and elsewhere that the rise of Asia has decimated their industrial power base. Finally, new technologies enable much greater flexibility and customerisation, with production shifting closer to the consumer. The result is that the complex global value chains that emerged prior to the 2007/2008 global financial crisis are now contracting and moving closer to end markets.

With its large and growing population, these developments are to Africa's potential advantage.

In Chapter 5, I recounted how the transformation of the agricultural sector assisted many countries in Asia in alleviating poverty and improving general well-being. Agriculture has served as a stepping stone for many poor countries. Once economies gained some momentum and basic education and literacy had shown sufficient progress, these countries pursued a manufacturing transition that was facilitated by favourable demographics and determined leadership. This eventually led to unprecedented rates of economic growth and improved incomes.

This is the history of the Japanese economic miracle that took place between 1950 and 1990, which was repeated in South Korea, Hong Kong, Macau, Singapore, Brunei, Taiwan and recently China. Countries such as Brazil, Indonesia, Malaysia, Mexico, Philippines, South Africa and Turkey

${ }^{9}$ Lund, S., Manyika, J., Woetzel, J., Bughin, J., Krishnan, M., Seong, J., and Muir, M. McKinsey\&Company ed., 2019. Executive Summary. In: Globalization in Transition: The Future of Trade and Value Chains. New York: McKinsey Global Institute. And also Dollar, D., 2019. Executive Summary. In: Technological Innovation, Supply Chain Trade, and Workers in a Globalized World. Geneva: World Trade Organization. 
also experienced substantive growth for several years as a result of industrialisation, but generally not at the rates and not for the extended period seen in Asia.

In Africa, Rwanda and Ethiopia have embarked upon a similar pathway and the results are visible for all to see-these countries have the most rapid improvements in indices of well-being on the continent.

\section{The Contribution of Services to Growth}

The focus that I place on an activist government, going up the agriculture value chain, export-oriented manufacturing and investments in human capital should not be misconstrued. The contribution from services is expanding at all levels of income, and most rapidly in low-income countries. This has become known as the servicification of the global economy, and reflects the extent to which services have become an integral requirement of agriculture, manufacturing and other sectors. And at high levels of development, financial services, computer and software services, as well as transport and distribution services have become a very dynamic requirement for continued growth. But high-value services constitute a very small segment of the large and growing services sector in Africa, much of which is in the informal retailing sector. ${ }^{10}$

At low levels of development, predominantly service-based economies have less ability to export or trade. Lower export earnings mean a weaker ability to buy advanced technology from abroad, which in turn leads to slower growth. According to Célestine Monga, writing for the African Development Bank in 2017, the problem is that at low levels of development, 'most services are low-productivity, subsistence, and even informal activities that may help households escape poverty, but are not sustainable sources of growth'. ${ }^{11}$

India is often considered an example of a country that, until recently, pursued a services-led growth strategy. The contribution of the services sector to GDP overtook that of agriculture in 1975 but the contribution of manufacturing to GDP only overtook agriculture three decades later. India's developmental model has been unique among major economies in the manner in which it has shifted from low-end agriculture to low-end

\footnotetext{
${ }^{10}$ Szirmai, A., 2009. Is Manufacturing Still the Main Engine of Growth in Developing Countries? [Online] Available at: https://www.wider.unu.edu/publication/manufacturing-still-main-enginegrowth-developing-countries.

${ }^{11}$ Monga, C., 2017. Industrialization: A Primer. In: Industrialized Africa-Strategies, Policies, Institutions, and Financing. Abidjan: African Development Bank Group.
} 
services without major industrial expansion. On its Current Path, Africa is following in India's low-growth footsteps. India's inward-looking economic model has relied on domestic markets more than exports, on consumption more than investment, on services more than industry and on high-tech more than low-skilled manufacturing. ${ }^{12}$

The early growth in services and the fact that India only recently entered a favourable demographic window—a period discussed in Chapter 4 in which there is a large working age population relative to the dependent population-are two important reasons for India's lower-than-expected growth over a number of decades (derogatorily referred to as its 'Hindu levels of growth'). Since 1991, economic liberalisation has partly unshackled an economy stifled by over-regulation, corruption and lack of competition. Furthermore, education levels are improving but India is still not living up to its potential although a convergence of factors, including improvement in the ratio of working age persons to dependents, prioritisation of investment in infrastructure and greater emphasis being placed on expanding the manufacturing sector offers prospects for improvement.

\section{The Impact of the Diffusion of Knowledge}

In a widely acclaimed book on the impact of information technology on globalisation, aptly titled The Great Convergence, ${ }^{13}$ Richard Baldwin argues that knowledge flows that consist of data, information searches, communications, transactions and video, dominate new globalisation instead of physical goods and finance flows across borders. ${ }^{14}$ For example, in 2016 cross-border flows in data were 45 times bigger than a decade before. ${ }^{15}$

Global flows of knowledge contribute to economic growth and present an opportunity for lagging countries to catch up through investment in information and communications technology (ICT). In theory, individuals can directly participate in globalisation by using digital platforms to study, find

\footnotetext{
${ }^{12}$ Freemantle, S., and Stevens, J., 2010. Lessons for Africa Inherent in India’s Meteoric Economic Ascent, Economics: BRIC and Africa, Standard Bank, 9 June, p. 5.

${ }^{13}$ Baldwin, R., 2016. The Great Convergence: Information Technology and the New Globalization. Cambridge: Harvard University Press.

${ }^{14}$ McKinsey Global Institute, 2016. Digital Globalization: The New Era of Global Flows. New York: McKinsey\&Company.

${ }^{15}$ McKinsey Global Institute, 2017. What's Now and Next in Analytics, AI, and Automation. [Online] Available at: https://www.mckinsey.com/featured-insights/digital-disruption/whats-now-andnext-in-analytics-ai-and-automation.
} 
jobs, showcase their talent and build networks. In practice, this opportunity is limited to those who are connected to the internet and who have the inclination, knowledge and interest to pursue it.

This caveat aside, ICT-led globalisation and associated knowledge flows are undermining the previous competitive advantage that industrialised countries had, and is changing the outlook for global value chains. The reason for this is that an increased number of jobs in the developed world are now in direct competition with jobs in emerging economies. The cross-border flow of data and knowledge has broken the monopoly that workers in wealthy nations had on the use of advanced industrial-manufacturing intellectual property.

While globalisation has had a disruptive impact in much of North America and Europe, where it has fuelled populist politics, the phenomenon has had a cohesive impact on emerging Asia, where the middle class has flourished and millions of people have been lifted out of poverty.

In an interconnected and globalised world knowledge flows inevitably undermine the concept of country comparative advantage-even in those countries that are part of integrated trade blocs, such as the United StatesMexico-Canada Agreement (USMCA), the European Union (EU) and the numerous bi- and plurilateral trade agreements in East and Southeast Asia, where regional value chains have been well established. ${ }^{16}$ Financial flows are already generally deregulated, knowledge is also now flowing more freely across boundaries - only labour mobility remains restricted.

In response to the impact of this 'new globalisation', industrialised countries have embraced policies to protect their knowledge-excessive use of patent protection being an important example-as well as requirements for minimum labour standards and the like. Conversely, emerging factory economies have embraced policies that foster knowledge sharing and creation. It is for this reason that China champions globalisation (despite having significant domestic barriers to foreign companies), while the previous advocate of free trade, the USA, now seeks to protect its domestic manufacturing sector from foreign competition. It does so by withdrawing or renegotiating trade agreements that now include a much higher domestic and labour content requirements, thereby raising the bar for less developed countries.

The problem for the US and other high-income economies is that digital communication, the internet and the ICT revolution has broken

\footnotetext{
${ }^{16}$ Stiglitz, J. E., 2017. Introductory Remarks: Promoting Sustainable Industrial Policies. In: Industrialize Africa: Strategies, Policies, Institutions, and Financing. Abidjan: African Development Bank Group. Ethiopia, Kenya, Morocco, the Seychelles, South Africa, and Tanzania have managed to make strides into GVCs. Manufacturing leads the integration into GVCs, ahead of agriculture and business services.
} 
the monopoly industrialised nations had on knowledge and even on copyright. The result of these changes is that barriers faced by manufacturers and specific industries and services in emerging countries, including in Africa, are constantly being lowered, often quite dramatically.

Trends in robotics, automation, computerised manufacturing and artificial intelligence all appear to reduce the advantage of low labour cost locations, but not necessarily to the detriment of Africa. Originally corporations sought to locate manufacturers in those countries with the cheapest labour. Today rapid growth in multinationals and consumers occurs within emerging rather than developed economies, hence in Vietnam, Malaysia, India and eventually also in Africa. According to one estimate, by 2025 almost half of the world's largest companies will have headquarters in emerging markets and closer to consumer growth. ${ }^{17}$ These trends will first benefit Asia but are also beginning to be felt in Africa.

A variety of digital technologies (particularly in the media), new materials (such as bio or nano-based materials) and new processes (such as 3D printing, not to mention artificial intelligence, and robotics) threaten to disrupt existing manufacturing patterns. Collectively these new trends have caused widespread concern about the nature and availability of jobs in the future (discussed in Chapter 9) and our understanding of economic growth theory. But at the moment it seems as if the future should see the evolution of a more distributed global economy where manufacturing and services are closely linked and value chains are shorter and closer to the future markets. All offer opportunities to Africa. Generally, new technology decreases the required input costs of manufacturing and it will become cheaper to manufacture, particularly for smaller production runs. Technologies such as 3D printing may in due course put an end to the smokestack factory model of production and perhaps the world could even see the evolution of something akin to a cottage industry model. ${ }^{18}$

Production is therefore experiencing a shift towards customisation for millions of niche markets by consisting of smaller production runs closer to the end markets and greater flexibility. ${ }^{19}$ The local manufacturer of says a spare part for a car or a replacement gear in a machine will be able to purchase the plan from the cloud and print locally. That means no more

\footnotetext{
${ }^{17}$ Ibid., pp. 16 and 20.

${ }^{18}$ African Center for Economic Transformation, The Future of Work in Africa-the impact of the fourth industrial revolution on job creation and skill development in Africa, 2018.

${ }^{19}$ De Backer, K., and Flaig, D., 2017. The Future of Global Value Chains: Business as Usual or "a New Normal"? Paris: OECD Publishing, p. 21.
} 
international shipping, tracking or customs is required. Instant gratification, at a lower environmental cost.

Ghanaian entrepreneur and president of mPedigree, Bright Simons ${ }^{20}$ refers to this as the rise of 'Alibaba industrialisation'. He writes eloquently about the 'unsung industrial revolution underway in places like Ghana, Uganda, Senegal and Côte d'Ivoire' that is powered by 'a worldwide revolution in modular design, multi-purpose machinery, efficient small-batch production, global SME-SME [small and medium enterprises] engagement, new forex transfer practices, and the growing strategic transformation of China's latephase industrial players'. This is a world where small- and medium-sized Chinese suppliers provide large chunks of the industrial jigsaw and 'African hustlers and unconventional industrialists act as shuttle-brokers of the various factors of production between China and Africa'. The fourth industrial revolution and digitisation therefore make it easier for African states to become part of value chains from which they were previously excluded.

One of the unforeseen results of lower barriers to entry is that it allows companies to venture into new areas outside their traditional area of specialisation. Startups can quickly go up the productivity curve to threaten established businesses. It is even evident in something as established as the manufacturing of cars where companies such as BYD in China threaten to outflank traditional car manufacturers in Germany, the USA, Japan and South Korea by investing heavily in future electric vehicle technologies.

Instead of an ownership economy, digital platforms also allow and facilitate the development of a sharing economy - this is where individuals rent or borrow goods and services for a specific time or task rather than to buy and own them.

\section{Manufacturing in Africa}

In their 2016 multi-year study of industrial development, Carol Newman and her co-authors ${ }^{21}$ compared eight African countries with Cambodia and Vietnam and offer a number of reasons that, taken collectively, explain Africa's lack of industry.

\footnotetext{
${ }^{20}$ Simons, B., 2019. Africa's Unsung "Industrial Revolution". [Online] Available at: https://www.cgdev. org/blog/africas-unsung-industrial-revolution?utm_source=190326\&utm_medium=cgd_email\&utm_ campaign $=$ cgd_weekly.

${ }^{21}$ Newman, C., Page, J., Rand, J., Shimeles, A., Söderbom, M., Tarp, F., 2016. The Pursuit of Industry: Policies and Outcomes. In: Manufacturing Transformation: Comparative Studies of Industrial Development in Africa and Emerging Asia. Oxford University Press.
} 
Firstly, is the widely held belief that the initial conditions for industrial development did not exist in Africa, including core infrastructure such as roads and rail, and human capital-basically an educated, healthy workforce. Furthermore, there were barriers to entry and the financial sector is not large or sophisticated enough, with small banks and underdeveloped financial markets being the norm. Without greater financial depth, many African countries have long struggled to attract larger investments.

However, at the time of their industrialisation, these conditions also did not exist in Japan, the so-called Asian Tigers (Hong Kong, Singapore, South Korea and Taiwan) or China. Greater financial depth, core infrastructure and a better-educated workforce developed in response to incentives, policies and effort. Governments are responsible for creating the right incentives to allow physical, human, social and knowledge capital to develop. That, in turn, requires a governing elite committed to economic growth and sufficient government capacity to formulate and implement policy.

Secondly, few African countries (Mauritius is a rare exception), set out and implemented a concerted package of public investments, appropriate policy and institutional reforms to increase the share of industrial exports in GDP. In the majority of African countries, little or no consistent effort was made to boost non-traditional exports, which still mostly consist of commodities.

Thirdly, contrary to successes achieved elsewhere, most African governments have paid little or no attention to making special economic zones (SEZs) work. SEZs have played a large part in the successful industrialisation in Asia. It allowed export-oriented industrial agglomerations to benefit from the advantages of being in close proximity to knowledge-intensive institutions including foreign and domestic companies that are more productive, research institutes and universities, which in turn led to information and knowledge spillovers.

The provision of improved social services and infrastructure in a limited physical area attracts foreign companies and high-quality staff. ${ }^{22}$ In lowincome countries, the domestic industry generally benefits from positive knowledge spillovers from foreign-owned firms, especially if it's part of the same value chain. Since African governments did not pursue the establishment of local value chains, African firms did not benefit. ${ }^{23}$ Instead, manufacturing firms have been dispersed across urban areas (instead of located in close proximity to one another) with limited requirements or incentives to source locally, train locals and establish local value chains. ${ }^{24}$

\footnotetext{
${ }^{22}$ Ibid., p. 18.

${ }^{23}$ Ibid., p. 19.

${ }^{24}$ Ibid.
} 
African governments also did not invest in high-quality infrastructure in SEZs, did not promote these zones or bring in professional management. African SEZs are generally not connected to domestic value chains, since the practice (if not policy) of governments was to treat them as stand-alone enclaves. $^{25}$

Fourthly, even though African governments created agencies and boards that advocated for foreign direct investment, this was done without real commitment and implementation support, which explains why these efforts achieved very little. ${ }^{26}$ For this reason most African countries linger at the bottom of various indices concerning the ease of doing business and attraction to foreign investment.

Finally, a large number of African countries such as Ghana, Kenya, Mozambique, Nigeria, Senegal and Tanzania have embarked on investment reforms in an effort to improve the physical, institutional and regulatory environments in which firms operate. However, active efforts to improve the competitiveness of domestic industries or practical measures to reduce trade friction costs resulting from poor trade logistics have not accompanied these reforms. ${ }^{27}$

Bad luck has also played a role in Africa's inability to industrialise. When African economies again spluttered into life at the end of the twentieth century, they not only had to compete with the industrial North but now also with a number of countries in East Asia, including China.

\section{Composition of African Economies}

Current levels and potential for expansion of manufacturing differ greatly between countries and regions. At roughly $20 \%$ of manufacturing value added to GDP, North Africa is the most industrialised region on the continent and West and East Africa the least industrialised (both at below $12 \%)$.

On average, the contribution of manufacturing to African economies has steadily declined since independence, and never reached the manufacturing peak share of $20-35 \%$ of GDP that was achieved in Europe and North America. After that peak in manufacturing employment and output in the

\footnotetext{
${ }^{25}$ Newman, C., Rand, J., Page, J., Shimeles, A., Söderbom, M., Tarp, F., 2016. Can Africa Industrialize? In: Manufacturing Transformation: Comparative Studies of Industrial Development in Africa and Emerging Asia. Oxford University Press. Also see Mills, G., 2019. A Tale of Two Free Zones: Learning from Africa's Success. The Brenthurst Foundation Discussion Paper 01/2019, February.

${ }^{26}$ Ibid., pp. 17-20.

${ }^{27}$ Ibid., p. 12.
} 
West, wages increased and employment and output in the manufacturing sector declined and, with some exceptions, services became an even more important source of growth at high levels of income. Consumers had more money to spend on services while the requirement for services in all sectors grew, and growth in this sector therefore accelerated. ${ }^{28}$

Figure 8.1 presents the sectoral composition of larger African economies as reflected in the World Bank open data portal, with countries ranked according to the contribution of manufacturing to GDP. According to the Bank data there is no statistically significant manufacturing in Mali, Sudan and Chad.

With a few exceptions, Africa's economies are dominated by large, lowproductivity services sectors. Generally the contribution from agriculture is lowest among upper-middle-income countries and highest among lowincome countries. The contribution from energy (not shown separately) and manufacturing is the opposite from agriculture, with low-income countries having the smallest energy and manufacturing sectors.

Sierra Leone has the largest contribution from agriculture to GDP at $60 \%$ and South Africa is among the smallest at slightly more than $2 \%$. Yet, South Africa, which has an efficient commercial farming sector, is one of the few African countries that is largely self-sufficient in terms of foodstuffs. Countries like Liberia, Mali, Niger, Chad and Guinea-Bissau all have very large agricultural sectors as a portion of their economy but are all net food importers-and import dependency is set to expand significantly.

The energy sector (not shown separately) makes the smallest contribution to GDP in Togo, whereas in South Sudan and Equatorial Guinea it constitutes almost one-third of the economy. Other countries where energy this sector makes up a large portion of the national economy are the Republic of Congo, Angola, Libya and Algeria.

Lesotho, Djibouti and the Seychelles, have the smallest economic contribution from the raw materials sector. The two countries with the largest contribution from raw materials are Guinea (gold and aluminium ore), Zambia (copper) and Mauritania (mostly iron ore and phosphate).

The countries with the smallest services sector are Togo, Sierra Leone, Guinea-Bissau, Chad and the Democratic Republic of Congo at 38-34\%. The services sector constitutes more than 60\% of GDP in South Africa, Cape Verde, Mauritius, Seychelles, São Tomé and Príncipe and Djibouti.

Over the last two decades, the information and communication sector (ICT) has overtaken agriculture as the third largest contributor to GDP by

${ }^{28}$ Mckinsey \& Company, 2012. Manufacturing the Future: The Next Era of Global Growth and Innovation. New York: Mckinsey Global Institute. 


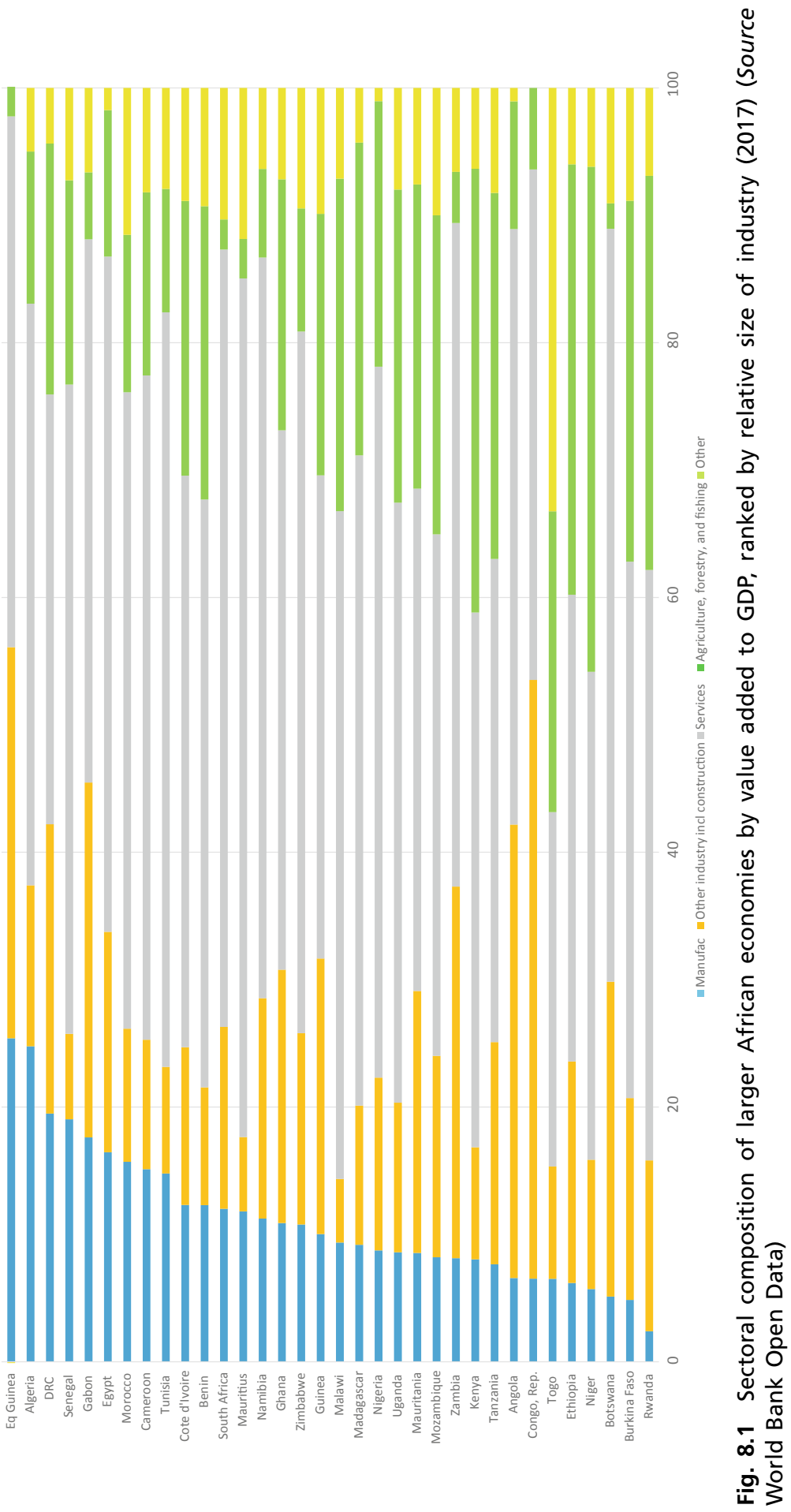


value globally (at around six percent of GDP), and it has become particularly important in high-income economies. Whereas the ICT sector is responsible for only one percent of the value-add to GDP in low-income countries, it contributes almost eight percent to GDP in high-income countries. Despite its relatively small contribution to added value, in many instances ICT is a growth multiplier as countries go up the GDP per capita ladder because it facilitates knowledge exchanges, including the effective functioning of regional and multinational value chains that include goods and services.

However, Africa's upper-middle-income economies trail behind those in the rest of the world in terms of the contribution made by ICT to the economy by an average of two percentage points. Only in Mauritius does ICT contribute more than five percent of GDP. In addition to the focus on manufacturing, a focus on ICT can also increase growth in Africa particularly as a means to deliver more effective education and improve service delivery such as the roll-out of identification systems and grants discussed in the previous chapter. The contribution of ICT to GDP for upper-middle-income countries in Africa is only half the global average for that group.

\section{Industrialisation and Growth in Africa}

From the preceding analysis, two points become apparent. The first is simply the low levels of manufacturing and ICT in Africa relative to comparable regions such as South America and South Asia. From 1999 to 2018, the manufacturing value added to GDP in lower-middle and upper-middleincome Africa is, respectively, around 9 and 11 percentage points below the global average for these two country groupings. Thus, on a comparative basis, Africa is significantly under-industrialised.

In a 2017 working paper for the African Development Bank, Bhorat et al., describe a sub-Saharan African productive structure that is inherently characterised by lower levels of economic complexity, which informed the notion of limited productive capabilities ... the African manufacturing sector is marginal in nature and points to limited employment opportunities' ${ }^{29}$

The second is the trend towards deindustrialisation in key upper-middleincome economies, particularly in South Africa and Mauritius, and until recently also in Algeria. Among others, this decline reflects the extent to

\footnotetext{
${ }^{29}$ Bhorat, H., Kanbur, R., Rooney, C., \& Steenkamp, F., 2017. Sub-Saharan Africa’s Manufacturing Sector: Building Complexity. African Development Bank Group, Working Paper Series No. 256, May. In this, understanding consists of the diversity of firms and productive capabilities described as nontradable networks of collective know-how, such as logistics, finance, supply and knowledge networks.
} 
which Asian and other exporters have successfully penetrated markets in the region. ${ }^{30}$

The percentage of GDP consisting of services has steadily increased since the 1980s to an estimated 57, 52 and 47\% average for Africa's upper-middle, lower-middle and low-income country groupings, respectively. By 2040 these numbers would all be close to $60 \%$. Whereas manufacturing and high-end services have grown in other regions such as in East, Southeast and South Asia, this has not occurred in Africa.

Africa produces about US $\$ 500$ billion of manufactured goods per annum. In a recent book, Acha Leke, Mutsa Chironga and Georges Desvaux argue that this could be doubled if two-thirds were designated for local consumption. ${ }^{31}$

In this context, China's increased role in manufacturing in Africa in recent years (as opposed to exporting to Africa) presents an interesting paradox. ${ }^{32}$ For example, the largest ceramic tile factory in Africa was recently built by China in Ethiopia. Nearly a third of the more than 10000 Chinese companies that McKinsey ${ }^{33}$ estimates are active in Africa and are involved in manufacturing. Together they are responsible for more than $12 \%$ of Africa's industrial production. Most of them are small and privately owned companies, not state-owned behemoths and their focus is on serving the needs of Africa's fast-growing domestic and regional market rather than on exports, with some exceptions such as Ethiopia.

The dominance of Chinese firms is even more pronounced in infrastructure where they claim nearly $50 \%$ of Africa's internationally contracted construction market. That observation raises the obvious question why, when the Chinese are constrained by the same lack of infrastructure, a poorly educated workforce and other conditions as locals, have such a large number of privately owned small Chinese companies been able to penetrate the African manufacturing market in a way that local and Western companies have not?

In fact, they appear to 'represent a long-term commitment to Africa rather than trading or contracting activities'. ${ }^{34}$ The McKinsey report goes on to argue that

\footnotetext{
${ }^{30}$ Bhorat, H., Kanbur, R., Rooney, C., and Steenkamp, F., 2017. Sub-Saharan Africa’s Manufacturing Sector: Building Complexity. African Development Bank Group, Working Paper Series No 256, May, pp. $9-10$.

${ }^{31}$ Ibid.

${ }^{32}$ Jayaram, K., Kassiri, O., and Sun, I. Y., 2017. The Closest Look Yet at Chinese Economic Engagement in Africa. New York: McKinsey\&Company.

${ }^{33}$ Ibid.

${ }^{34} \mathrm{Ibid}$.
} 
... 89 percent of employees were African... this suggests that Chineseowned business employ several million Africans. Moreover, nearly two-thirds of Chinese employers provided some kind of skills training ... Half of Chinese firms had introduced a new product or service to the local market, and onethird had introduced a new technology. In some cases, Chinese firms had lowered prices for existing products and services by as much as 40 percent through improved technology and efficiencies of scale. African government officials overseeing infrastructure development for their countries cited Chinese firms' efficient cost structures and speedy delivery as major value adds.

In short, if Chinese entrepreneurs and companies can enter and grow the manufacturing sector in Africa, why can't Africans?

Some self-defeating policies are self-evident. South Africa, for example, which has a large domestic vehicle manufacturing industry, could stipulate that the government will only procure locally produced vehicles for official use and in that manner support local industry, but it does not. An excessive regulatory burden including requirements for black economic empowerment ensure that South Africa's ability to compete against Chinese imports is steadily eroding.

On the other hand, there have been successful state efforts to support localised manufacturing development. Several years ago, Nigeria established a domestic cement industry by offering a four-year licence to import cement on the condition that the licence holder would invest in a domestic cement production plant. Today Nigeria is a net exporter of cement and the deal has created the richest African (Aliko Dangote). ${ }^{35}$

But the biggest opportunity to grow domestic manufacturing is with intraAfrican trade (see Chapter 11).

Close to $60 \%$ of African imports consist of manufactured goods by value, while the dominant export segment is in energy exports such as oil, coal and gas. Many of the imported goods can be manufactured locally and boost the value of intra-African trade. There is great potential to increase intra-African trade in a host of foodstuffs, beverages and cigarettes, rubber and plastics, electronics and non-metallic mineral products. ${ }^{36}$

Replacing imported manufactured goods with goods made in Africa will not be easy since global value chains have improved efficiencies and reduced prices, making it difficult for new entrants to compete. Still, it remains

\footnotetext{
${ }^{35}$ Dangote Cement has three plants in Nigeria with operations in ten African countries. It produces around 44 million metric tons of cement every year and plans to increase output by a third in the next two years. See Dangote Cement at www.dangotecement.com.

${ }^{36}$ Oosthuizen, M., Linde, E., Durrant, K.-L., and Gopaldas, R., 2018. The Future of Energy and Power Utilities in Africa. Johannesburg: Gordon Institute of Business Science, p. 65.
} 
a crucial step in the transformation of African economies and previous sections have indicated that global value chains are evolving with potential opportunities for Africa. ${ }^{37}$

Growth in Africa's manufacturing sector requires a stable and facilitating policy framework, government support and incentives.

The entry point for manufacturing traditionally involved labour-intensive segments of regional manufacturing value chains, meaning that labour costs needed to be competitive. Given that Africa suffers from various disadvantages, such as poor physical infrastructure, ${ }^{38}$ a high disease burden and poor rule of law, low regulatory and policy quality and a lack of policy certainty among others, the general view is that African labour costs need to be cheap enough to compensate for these deficits. ${ }^{39}$

However, a 2017 study on Africa's manufacturing labour costs by Alan Gelb and others ${ }^{40}$ concluded that poor African countries have higher labour costs than their average income levels would suggest. The study compared 12 African countries to 17 non-African countries. Only Ethiopia compared favourably. In all other African countries included in the study, labour costs were higher than those of their non-African peers. In this regard South Africa stands out as a middle-income country with particularly high labour costs and a very capital-intensive industrial sector-partly explaining its extraordinarily large burden of unemployed.

Manufacturing labour costs in low- and lower-middle-income countries Kenya, Tanzania and Senegal — three relatively stable coastal countries with strong business sectors-are higher than in Bangladesh, a country with a comparable World Economic Forum (WEF) competitiveness rating and income levels.

However, one of the effects of the fourth industrial revolution is the declining importance of labour costs in the location of industry while the trend to locate manufacturing closer to end markets has also been discussed.

For these and other reasons, Carol Newham and her co-authors believe that industrialisation in Africa remains possible, although its shape and form

\footnotetext{
${ }^{37}$ Bhorat, H., Kanbur, R., Rooney, C., and Steenkamp, F., 2017. Sub-Saharan Africa's Manufacturing Sector: Building Complexity. African Development Bank Group, Working Paper Series No 256, May, p. 92.

${ }^{38}$ Page, J. 2017. Industrial Policy in Africa: From State Leadership to the Investment Climate. In: Industrialize Africa: Strategies, Policies, Institutions, and Financing. Abidjan: African Development Bank Group, p. 81.

${ }^{39}$ Newman, C., Page, J., Rand, J., Shimeles, A., Söderbom, M., Tarp, F., 2016. The Pursuit of Industry: Policies and Outcomes. In: Manufacturing Transformation: Comparative Studies of Industrial Development in Africa and Emerging Asia. Oxford University Press, p. 5.

${ }^{40}$ African Development Bank. 2017. Industrialize Africa-Strategies, Policies, Institutions, and Financing. African Development Bank Group, p. 46.
} 
will differ from that previously experienced elsewhere. Writing in 2016 they offer three considerations:

First, economic changes are taking place in Asia that create a window of opportunity for late industrializers elsewhere to gain a toehold in global markets. Second, the nature of manufactured exports themselves is changing. A growing share of global trade in industry is made up of stages of vertical value chains - or tasks - rather than finished products. Trade in tasks offers late industrializers an opportunity to enter global markets in areas suited to their factor costs and endowments of skills and capabilities. Third, trade in services and agro-industry is growing faster than trade in manufacturers. These industries without smokestacks' broaden the range of products in which Africa can compete, and a number of them are intensive in locations specific factors abundant in Africa. ${ }^{41}$

And eventually, because Africa is growing so much slower than other regions, wages in Africa will become competitive and offset the productivity advantage of incumbent industrial producers, including those in East Asia.

Even so, according to a 2017 analysis by Alan Gelb and others at the Center for Global Development, ${ }^{42}$ most African countries (with the exception of Ethiopia) are still some way from this point. China and other countries in East Asia are, however, restructuring their economies to meet growing domestic demand, which will create space for Africa to compete with countries such as Bangladesh as the low-end manufacturing location of choice for the future. ${ }^{43}$

\footnotetext{
${ }^{41}$ Newman, C., Rand, J., Page, J., Shimeles, A., Söderbom, M., Tarp, F., 2016. Can Africa Industrialize? In: Manufacturing Transformation: Comparative Studies of Industrial Development in Africa and Emerging Asia. Oxford University Press, p. 258.

${ }^{42}$ Gelb, A., Meyer, C., Ramachandran, V., and Wadhwa, D., 2017. Can Africa Be a Manufacturing Destination? Labor Costs in Comparative Perspective. Center for Global Development Working Paper 466, 15 October, p. 8.

${ }^{43}$ Newman, C., Rand, J., Page, J., Shimeles, A., Söderbom, M., and Tarp, F., 2016. Can Africa Industrialize? In: Manufacturing Transformation: Comparative Studies of Industrial Development in Africa and Emerging Asia. Oxford University Press, p. 259. Gelb question some of these conclusions: 'for any given level of GDP, labor is more costly for firms that are located in Sub-Saharan Africa. However, we also find that there are a few countries in Africa that, on a labor cost basis, may be potential candidates for manufacturing - Ethiopia in particular stands out'. Gelb, A., Meyer, C., Ramachandran, V., and Wadhwa, D., 2017. Can Africa Be a Manufacturing Destination? Labor Costs in Comparative Perspective. Center for Global Development Working Paper 466, 15 October.
} 


\section{Modelling the Impact of Industrialisation: The Made in Africa Scenario}

This section briefly presents a set of intervention clusters modelled within IFs to emulate industrialisation in Africa with a time horizon to 2040, and compares its impact to the Current Path.

Clear industrial policy and determined government leadership and action are critical if African economies are to grow more rapidly. For this reason, a first cluster of interventions increases investment in the economy. It reflects the determined efforts by forward-looking African governments to industrialize.

A second cluster of interventions aggressively increases government expenditure in research and development to twice the expected level in 2040 on the Current Path (from the current African average of $0.12 \%$ of GDP to $0.23 \%$ by 2030 and $0.26 \%$ by 2040 ), provides export support to the manufacturing and ICT sectors, and modestly raises prices on manufacturing and ICT imports. An increase in expenditure on research and development is a particularly powerful driver of improvements in multifactor productivity.

A final intervention is to improve economic freedom as a proxy for lowering the barriers to entry for foreign companies and ease of doing business for small businesses. ${ }^{44}$

At this point I need to remind the reader that the exploratory interventions modelled for this chapter (and the book as a whole) were all done at a continental or country-income level and were neither tailored to improve the use of labour, capital or multifactor productivity at the national level nor to primarily focus on industrialisation in middle as opposed to low-income economies. At best, the efforts presented here emulate a continent that commits to actively pursue greater industrialisation and serves to illustrate potential, rather than map out the specific associated benefits.

With that caveat in mind, Fig. 8.2 presents the shift in the sectoral composition that would occur at the continental level as a result of the Made in Africa scenario. The manufacturing sector is, by 2040, 2.1 percentage points larger than it otherwise would have been (a difference of roughly US\$355 billion) and the ICT sector about 0.2 percentage points larger (US $\$ 45$ billion difference). Agriculture declines more rapidly than in the Current Path and the services sector is almost one percentage point (or US $\$ 425$ billion) smaller. But because the African economy grows more rapidly, all sectors are actually

\footnotetext{
${ }^{44}$ IFs used the economic freedom index from the Fraser Institute as a proxy for the level of economic freedom and the intervention means that Africa converges to the level of economic freedom of South Asia by 2030 .
} 


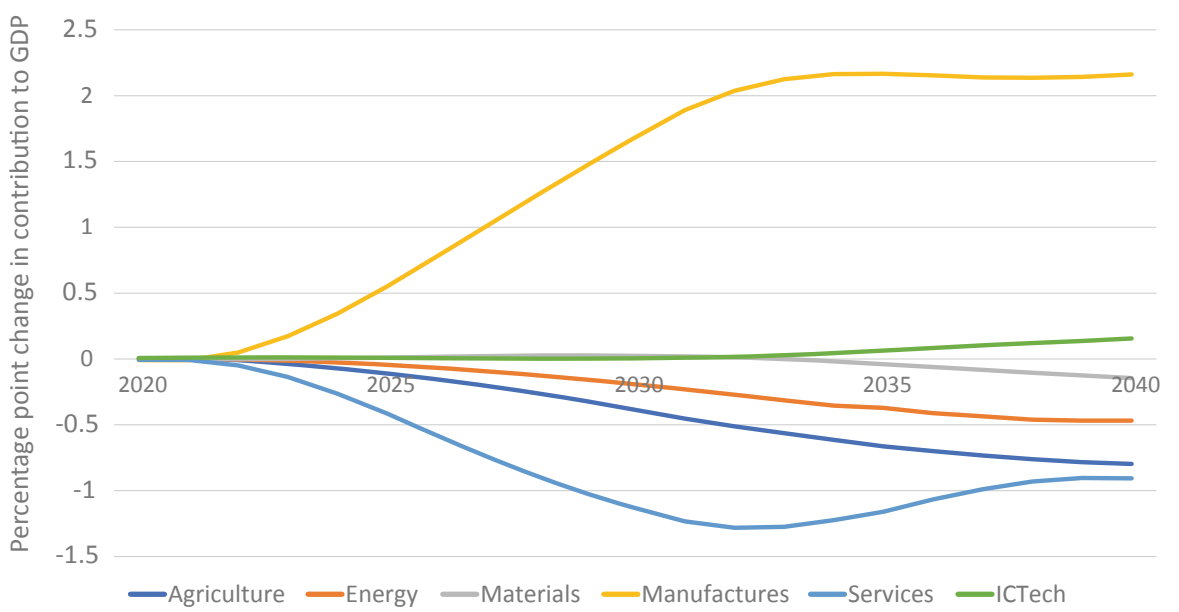

Fig. 8.2 Percentage point shift in sectoral contribution to African economy 2020 to 2040: Made in Africa compared to Current Path (Source IFs v7.45 initializing from IMF World Economic Outlook 2017)

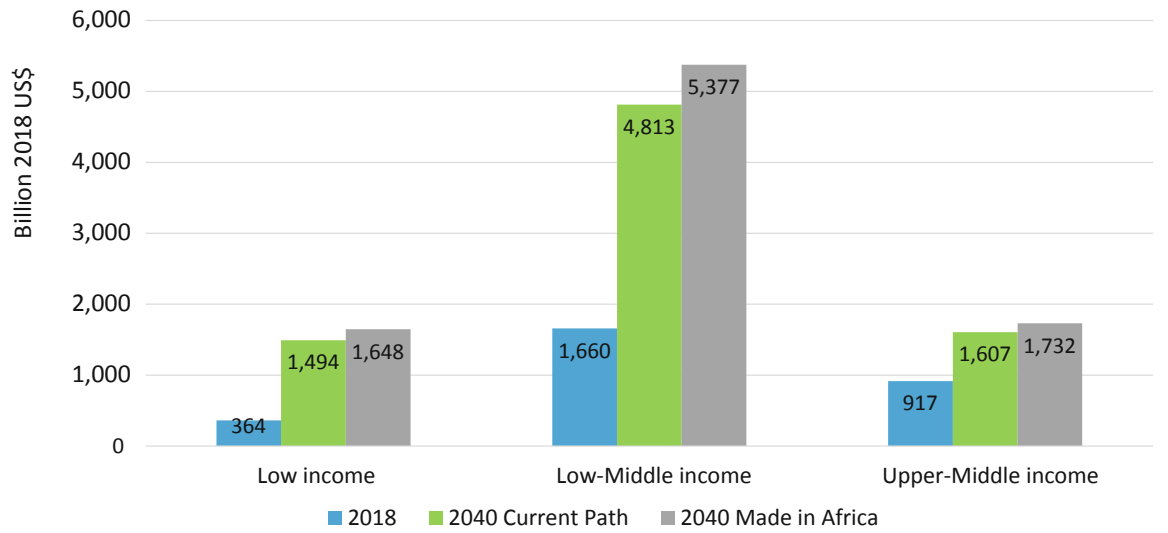

Fig. 8.3 Comparing GDP: Current Path vs Made in Africa (2018 to 2040) (Source IFs v. 7.45 initializing from International Monetary Fund World Economic Outlook 2017)

larger by 2040 than in the Current Path forecast. Services grow rapidly under all scenarios, constituting almost 60\% of the total African economy by 2040 .

Figure 8.3 presents the size of the African economy in 2018 and 2040 under the Current Path and Made in Africa scenario. Whereas, in 2018, the GDP of Africa is estimated at US\$2.9 trillion, it should, under the Current Path forecast, increase to US\$7.9 trillion at an average growth rate of $4.7 \%$ per annum to 2040. In the Made in Africa scenario, the 2040 African economy is substantially larger, at US $\$ 8.8$ trillion. Instead of the 
4.7\% average growth rate, in the Made in Africa scenario, Africa is now forecast to experience an average growth rate of $5.2 \%$.

The initial impact is limited but compound growth is incredibly powerful. Although the average difference between the Current Path and Made in Africa rate of growth is only 0.5 percentage points from 2020 to 2040, the result is, by 2040, and African economy that is a full ten percent (or almost US $\$ 850$ billion) larger in the Made in Africa scenario than in the Current Path forecast. The rates of growth also accelerate over the forecast horizon and since it alters the composition of Africa's economy, it sets the continent on a more positive growth trajectory.

The Made in Africa scenario is significantly more modest than the wildly optimistic forecast published by McKinsey in their 2017 report Lions on the move II: Realizing the potential of Africa's economies. According to this report, Africa could double its manufacturing output by 2025 'provided countries take decisive action to create an improved environment for manufacturers'. ${ }^{45}$

In the Made in Africa scenario, low-income African economies are forecast to be roughly $10 \%$ larger in 2040 than it would be in the Current Path forecast (equivalent to US\$154 billion) and increases rapidly thereafter. The economies of low-middle-income and upper-middle-income countries would be, respectively, 12\% (US\$565 billion) and seven percent (US\$125 billion) bigger.

Income levels increase substantially in the Made in Africa scenario. By 2040 the average African would have an income that is US\$514 more than in the Current Path with the largest increases in upper-middle-income countries at US\$890 (in PPP). There is also a small decline in inequality using the gini index.

\section{Costs and Benefits of a Manufacturing Pathway}

A manufacturing pathway comes with short to medium-term costs relating to poverty and employment since it diverts expenditure towards higher-value activities against the promise of more rapid and sustainable growth. In addition, there are political constraints in Africa that are quite different to those of South East Asia. Countries like Bangladesh, Vietnam and others built their manufacturing success on the back of extreme labour exploitation in the thousands of factories and sweatshops that eventually made this region

\footnotetext{
${ }^{45}$ Bughin, J., Chironga, M., Desvaux, G., Ermias, T., Jacobson, P., Kassiri, O., Leke, A., Lund, S., van Wamelen, A., and Zouaoui, Y., 2016. Lions on the Move II: Realizing the Potential of Africas Economies. New York: Mckinsey \& Company.
} 
the global manufacturing hub. It is debatable if this pathway is open in the twenty-first century on a continent where democracy is at significantly higher levels and where the voice of the people readily translates into street protests and even violence.

That constraint aside, the analysis on poverty in Chapter 7 showed that extreme poverty was at $50 \%$ of the total African population in 2018 and that it would decline to $35 \%$ by 2040 , using the three income levels of extreme poverty now used by the World Bank.

In the Made in Africa scenario poverty levels marginally increase for a decade above the Current Path before the more rapid economic growth makes up for this initial increase. For example, at its peak in 2030, 25 million more Africans will be living in extreme poverty in low-income Africa than would be the case in the Current Path, But by 2040, 8 million less Africans will be living in extreme poverty. Thereafter the positive impact accelerates dramatically.

It is unclear if a manufacturing pathway will create more jobs in the short term, but it is certain to increase employment in the medium and long term as rates of economic growth accelerate. Quite likely the Made in Africa scenario will initially increase unemployment slightly before the economy starts growing more rapidly. In contrast, the blue-skies forecast by the McKinsey group is that an expanded and more productive manufacturing sector could already create six to 14 million stable jobs by $2025 .{ }^{46}$

These results point to two important conclusions. The first is the importance of additional measures to reduce extreme poverty, including efforts to directly support extremely poor families through social programmes like cash grants. The second is that the largest increase in poverty during the initial period of industrialisation will take place in low-income countries, which is why industrialisation should probably be pursued after countries have graduated to low-middle-income status.

None of these costs should, however, detract from the fact that eventually a growing manufacturing sector has important spillover effects on other sectors beyond more rapid growth. It generally leads to improved productivity in the agricultural sector and incentivises the development of higher-value services.

${ }^{46}$ Ibid., p. 14. 


\section{Conclusion: Promoting and Intensifying Local Production and Trade}

Since the 1970s, African economies have experienced a limited-as well as limiting-form of structural transformation from low-productivity agriculture to low-end services. Manufacturing and industrial development have never taken off in Africa. In fact, the continent appears to be deindustrialising from already low levels.

By comparison, countries in East Asia grew rapidly and over sustained periods of time after they had achieved food security because of the rapid productivity gains that followed determined efforts by an activist government to move labour from low to higher-productivity sectors of the economy and to invest in the same. Labour typically moved from subsistence agriculture to low-end manufacturing and then to increasingly complex manufacturing products.

Starting from a low base, where the majority of workers engage either in subsistence farming or informal services, Africa has more to gain from structural transformation than other developing regions, but to date it has not managed to achieve this. The primary reason why it is so crucial to grow Africa's manufacturing and high-end services sector is not only because of the potential that manufacturing has to create more formal sector jobs, but because it would change the productive structures of African economies and unlock more rapid growth. In fact, James Manyika and colleagues remind us that the contribution of manufacturing to an economy shifts as a nation matures and that in advanced economies, 'manufacturing promotes innovation, productivity, and trade more than growth and employment'. ${ }^{47}$ Eventually more rapid growth also translates into more employment.

Digital production-particularly through the impact of artificial intelligence, automation and robotics-will also play a role. Meanwhile, the continent needs to invest in lowering transport and infrastructure costs, ensure policy certainty and a low regulatory burden to compensate for Africa's relatively high labour costs. It also must ensure the success of trade integration to provide larger markets and rapid digitisation. Collectively this will attract and grow manufacturing.

In a future where more goods will be produced and consumed in regional rather than global markets and possibly in a much more distributed manner, Africa has considerable opportunities for industrialisation as well as regional trade (see Chapter 11). However, this will only happen if leaders in key

\footnotetext{
${ }^{47}$ Mckinsey \& Company, 2012. Manufacturing the Future: The Next Era of Global Growth and Innovation. New York: Mckinsey Global Institute.
} 
growth-locomotive countries embark on a deliberate effort to go up the manufacturing curve and establish and support SEZs, set clear industrial policies, provide relevant education and invest in the necessary digital backbone.

On this journey, ICT could play an important role in improving productivity in various sectors.

Without much greater emphasis on actively pursuing structural transformation of the economy towards more highly productive sectors, Africa will not be able to add value to its agricultural sector or develop higherend services. African economies must be infused with technology, otherwise Africa will remain poor.

The transition from low to higher productivity requires active governments that set up, nurture and support dynamic local industries and services, changing the dominant mode of production - in effect, changing society as a whole. These measures will need very careful, if not surgical, engagement by a competent and modern bureaucracy.

Taking a ten year or longer forecast horizon the Made in Africa scenario will create many more jobs than the Current Path forecast as economic growth accelerates, but in the shorter term too sharp a focus on manufacturing would limit job growth pointing to the need to complement the Made in Africa efforts with others. And generally the employment intensity of the manufacturing sector is declining globally when compared to the period when Asia experienced its most rapid manufacturing growth. ${ }^{48}$

It is against this backdrop that the next chapter looks at jobs and the changing nature of work in Africa.

\section{Further Reading}

Dani Rodrik. 2016. Premature Deindustrialization. Journal of Economic Growth, 21(1), pp. 1-33. https://www.nber.org/papers/w20935.

Farole, Thomas, and Deborah Winkler, eds. 2014. Making Foreign Direct Investment Work for Sub-Saharan Africa: Local Spillovers and Competitiveness in Global Value Chains. Directions in Development. Washington, DC: World Bank. https://doi. org/10.1596/978-1-4648-0126-6. ISBN: 978-1-4648-0126-6. License: Creative Commons Attribution CC BY 3.0.

\footnotetext{
${ }^{48}$ Levels of peak manufacturing employment have declined with each wave of industrialisation from around 30\% of employment with the first wave of smokestack industries in Europe two centuries ago to levels roughly half that of today. Bhorat, H., Kanbur, R., Rooney, C., and Steenkamp, F., 2017. Sub-Saharan Africa's Manufacturing Sector: Building Complexity. African Development Bank Group, Working Paper Series No. 256, May.
} 
World Manufacturing Forum. 2019. The 2019 World Manufacturing Forum Report: Skills for the Future of Manufacturing. Accessed 17 December 2019: https://www.worldmanufacturingforum.org/report-2019.

Open Access This chapter is licensed under the terms of the Creative Commons Attribution 4.0 International License (http://creativecommons.org/licenses/by/4.0/), which permits use, sharing, adaptation, distribution and reproduction in any medium or format, as long as you give appropriate credit to the original author(s) and the source, provide a link to the Creative Commons license and indicate if changes were made.

The images or other third party material in this chapter are included in the chapter's Creative Commons license, unless indicated otherwise in a credit line to the material. If material is not included in the chapter's Creative Commons license and your intended use is not permitted by statutory regulation or exceeds the permitted use, you will need to obtain permission directly from the copyright holder.

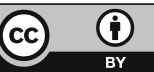

